\title{
Non-adherence to anti-retroviral therapy among HIV infected adults in Mon State of Myanmar
}

\author{
Win Lei Aye ${ }^{1,2^{*}}$, Apa Puckpinyo ${ }^{3}$ and Karl Peltzer ${ }^{4,5}$
}

\begin{abstract}
Background: The provision of Anti-Retroviral Therapy (ART) was started in Myanmar in 2005 in collaboration with the National AIDS Program and the private sector. Successful clinical management of HIV-infected patients is subject to optimal adherence. The aim of the study was to determine the prevalence of adherence to ART and identify factors associated with non-adherence to ART among HIV infected adults registered in a private sector setting in Mon State, Myanmar.
\end{abstract}

Methods: This cross-sectional study was conducted with adults living with HIV receiving ART at an HIV outpatient clinic between April and May 2016. A total of three hundred People Living with HIV(PLHIV) were interviewed using a pretested and structured questionnaire. The 30 days Visual Analog Scale (VAS) adherence instrument was used to assess the level of adherence. Multivariable logistic regression analysis was used to determine factors associated with non-adherence to ART.

Results: Among 300 patients (male $37.7 \%$ and female 62.3\%, with a mean age of 41.3 years, standard deviation 8.7), $84 \%$ reported $\geq 95 \%$ adherence to ART in the past month. Among $16 \%$ of those reporting non-adherence, major reasons for skipping the medication were being busy (23\%), being away from home (17.7\%) and being forgetful (12.3\%). In multivariable logistic rgeression, low behavioural skills on ART adherence (OR $=0.31,95 \% \mathrm{Cl}: 0.10-0.94)$, tobacco use (OR $=3.22,95 \% \mathrm{Cl}: 1.28-8.12)$, having disclosed their HIV status (OR $=0.07,95 \% \mathrm{Cl}$ : 0.01-0.69), having a partner who was not on ART (OR $=4.25,95 \% \mathrm{Cl}$ : 1.70-10.64) and among men, having erectile dysfunction $(\mathrm{OR}=15.14,95 \% \mathrm{Cl}: 1.41-162.66)$ were significant associated with ART non-adherence.

Conclusion: Non-adherence to ART was associated with individual moderating factors and behavioral skills. Priority measures such as addressing risk behaviour and behavioural change communication tailored to individual patients' lifestyles requires comprehensive interventions to improve adherence.

Keywords: Anti-retroviral therapy, HIV-infected adults, Myanmar, Non-adherence

\section{Background}

Approximately 35 million people were living with the Human Immunodeficiency Virus (HIV) worldwide in 2013, and 1.5 million people had died due to Acquired Immune Deficiency Syndrome (AIDS) related causes $[1,2]$. Life-saving HIV treatment, Highly Active Anti-Retroviral Therapy (HAART) is a unique tool in the AIDS response

\footnotetext{
* Correspondence: wlaye@iom.int

${ }^{1}$ Master of Primary Health Care Management Program, ASEAN Institute for Health Development, Mahidol University, Nakhonpathom, Thailand

${ }^{2}$ International Organization for Migration, Kamayut Township, Yangon, Myanmar

Full list of author information is available at the end of the article
}

which reduces mortality and moribidity. Declines in morbidity are usuallly measured by occurrence of specific opportunistic infections [3, 4] and Anti-Retroviral Therapy (ART) has lead to approximately 40.2 million life-years gained. Despite this evidence, twenty-two million, or three out of five people living with HIV (PLHIV), are still not able to access ART [5]. As hopes for ending the AIDS epidemic are dependent on providing HIV treatment to all who need it, access to Universal Health Care is also critical [4].

Since 2013, evidence and programmatic experience have led to reductions in HIV related mortality, morbidity and 
HIV transmission outcomes through earlier initiation of ART. When ART is able to be initiated earlier, the clinical outcome of PLHIV are improved [6]. As ART is scaled up in most of the countries in the world, it is necessary to understand why and how many people drop out of treatment programmes and what factors affect adherence to ART. The concept of an HIV "treatment cascade" is used to describe the entire process of HIV testing, linkage to care, initiation of ART, treatment adherence, and retention in care [4]. A cumulative cross-sectional cascade for HIV treatment and care in Myanmar 2014 reported that out of an estimated 212,000 PLHIV, only 91,000 knew their diagnosis and 85,626 were receiving anti-retroviral therapy [1]. In 2014, amongst ART patients in Myanmar, 9586 received a viral load test with only 8295 achieving suppression of viral load [1]. These reports indicate that only $40 \%$ of the PLHIV in Myanmar are prescribed ART and that among these individuals, only $11 \%$ received viral load testing and among them, only $87 \%$ have suppressed viral loads [1]. Thus, to achieve optimal clinical outcomes of treatment, attention to each step in the treatment cascade is critical.

To achieve a successful treatment outcome, HIV treatment requires more than $95 \%$ adherence levels $[7,8]$. Adherence research provides strong evidence that an HIV patient with non-adherence to ART has 3.87 times greater mortality rates than an adherent patient on the same treatment [9]. Individual factors contributing to non-adherence may include forgetfulness, being away from home, changes in daily routines, depression or other illness, limited knowledge of treatment benefits and substance use [10]. In a study in Ethiopia conducted among 974 ART patients, 13\% were found to have missed one, two or three or more doses when they took their prescribed anti-retroviral drugs (ARVs) during four days recall before interview [11]. In another study in Laos that assessed ART adherence among PLHIV adults receiving free ART at a hospital reported an alarming $40 \%$ of the study participants as non-adherent to ART. Patients in that study revealed numerous reasons for their actions, ranging from repoting being very busy to take their treatment to forgetfulness, drinking alcohol and substance use [12]. Moreover, a study in India reported that only $73 \%$ of patients on ART took their treatment with at least or over $95 \%$ adherence [13]. Furthermore, patients' perceived erectile dysfunction may be regarded as a relevant problem for $\mathrm{HIV}$-infected persons on antiretroviral therapy [14] and has been strongly associated with suboptimal ART adherence [15]. According to these studies, maintaining over 95\% adherence level among the PLHIV in developing countries is a crucial issue to maintain viral suppression, to minimize HIV related morbidity and mortality and there are many predictors that have been associated with ART non-adherence.
The concept of keeping treatment adherence should start from the earliest involvement in patient care. Retention in care of HIV-infected patients also reflects treatment success at the individual level $[16,17]$. Findings of studies in Myanmar for retention in care at private sector ART sites have shown that the reported retention in care at 60 months reached $72 \%$ in the 2012 [18] and $74 \%$ in the 2014 respectively [19]. Since individual treatment success is associated with retention in care, suboptimal retention is directly associated with negative outcomes on the long term effect on viral suppression and adherence outcomes [20]. Additionally, there are no routine assessments fo ART adherence among PLHIV in Myanmar since most of the settings are resource-limited. Finally, there are very few studies related with ART adherence for PLHIV in Myanmar. Therefore, there is a need to determine the level of adherence among PLHIV in Myanmar. It is important to know the rates of adherence to ART among PLHIV in Myanmar and which factors can be associated with non-adherence to ART. This research study will investigate adherence to ART in Myanmar and identify factors affecting the nonadherence among a sample of PLHIV adults receiving ART in the private sector in Myanmar.

\section{Methods \\ Study setting}

The study was carried out at an outpatient ART clinic in the private sector (defined as non-government provider) in Mon State, Myanmar. At the time of the study over 2000 PLHIV were registered at the study site, of which 1423 were on ART. The study site provided all treatment, care and support free of charge and clinical consultations were performed by medical doctors with counselling performed by dedicated nurse counsellors.

\section{Study design and participants}

The cross sectional study was performed from April to May 2016. The study population included HIV-infected adults $\geq 18$ years of age who were confirmed to be HIV positive and currently taking ART for at least one month at the outpatient clinic. The patients who met the inclusion criteria were invited to participate in the research, received an explanation of the purpose of the study and were asked for informed consent. Participants were drawn from the PLHIV ART patients list who consecutively attended the clinic for their follow up to receive ART and/or counselling after asking to participate in the research. To complement the questionnaire, some treatment-related information was extracted through the review of medical records with patients' informed consent. 


\section{Sampling}

The participants were selected by consecutive sampling. The initial sample size was estimated to be 272 with a power of $0.77 \%$. However, we were able to recruit 300 participants who met the inclusion criteria.

\section{Definition of adherence}

Adherence is the extent to which a person is taking the medicine as prescribed by physician and according to medical recommendations, inclusive of timing, dosing and consistency and correctly taking the drugs in terms of right doses, right times and following the dietary recommemdations [21]. Although there is no gold standard for measuring adherence to medication, many measurements of adherence assessment can be used such as self-reports, pill counts, medication event monitoring systems, pharmacy refill tracking and biological markers such as monitoring the level of viral load [22]. Among these measurements, self-report is easy for data collection and can also determine the reasons why patients are non-adherent [22]. Patients assume, however, they can accurately recall their behaviour and are providing sincere answers [23]. The rate of adherence to ART is the number of tablets that the patient has really taken divided by the number of tablets that the patient had to take multiplied by the number one hundred [24].

\section{Measurement}

We used the Adult AIDS Clinical Trials Group (AACTG) adherence instrument and 30 days visual analogue scale (VAS) to assess adherence. AACTG is four days recall method for measuring adherence that also assesses reasons of non-adherence [25]. VAS adherence assessment is the Medication Self-report Inventory that can be used to assess adherence to a single antiretroviral medication [26]. It is a self-reported ART measure that is simple to use and has been most extensively used [25]. The subjects are requested to place a mark at the point on a horizontal scale answering to the subject's best estimation of the proportion of medication doses taken with examples of $0,50 \%$, and $100 \%$ adherence over the past 30 days. Adherence was assessed by self-report adherence methods to categorize study the population in two outcome groups namely "adherence" and "non-adherence". VAS measures overall adherence for a longer time interval and wide assessment coverage. Adherence refers to the PLHIV took $\geq 95 \%$ of doses taken over the past 30 days. On the other hand, patients with $<95 \%$ of doses taken over the past 30 days, were defined as non-adherence.

The life Windows Information-Motivation-Behavioral Skill ART Adherence questionnaire (LW-IMB-AAQ) was used to assess adherence barriers [27]. Each LW-IMBAAQ item represents a barrier falling within the I (Information), M (Motivation), or B (Behavioral Skills) constructs.
Adherence information was assessed with nine items. Cronbach's alpha for information in this sample was 0.66. Adherence-related motivation is composed with two factors of personal motivation and social motivation to adhere to one's regimen. Personal motivation is represented as attitudes on treatment and beliefs about medications. Adherence motivation was assessed with ten items. Cronbach's alpha for this sub-scale was 0.58 . Behavioural skills (adherence 'self-efficacy', i.e. patient's perceived ability to follow medication regimen) was assessed with 14 items. The behavioral skills showed an internal consistency of $\alpha=0.60$ for this sample [27]. Response options to theinformation and motivation questions ranged from " $1=$ strongly disagree to $5=$ strongly agree". Response to items of behavioral skills includes $1=$ very hard to $5=$ very easy. As scoring instruction, the direction of 'correct' was assigned a value of one, while other response options were scored zero in all items of IMB constructs [24]. According to this instructions, for each participant score ' 1 ' for each item indicates a response towards adherence and score ' 0 ' indicates the item as a barrier. Scores for each domain of IMB (Information-Motivation-Behavioral skills) was split into three levels - low, moderate and high and the percentage of patients in each level will calculate.

Social support: Three items were drawn from the Social Support Questionnaire [28] to assess perceived social support. These items are responded to on 4point scales, $1=$ completely true, to $4=$ completely false, and summed to a score with a range of 3-12. Cronbach's alpha for this sample was 0.75 .

Internalized AIDS stigma was assessed with a 7-item AIDS-Related Stigma Scale [29]. Items are responded to from $1=$ strongly agree to $4=$ strongly disagree. Strongly agree and agree were converted to " 1 " and strongly disagree and disagree to "0", scale scores and represent total sum score was range 0-7. Cronbach's alpha for this stigma index was 0.80 in this sample.

HIV status disclosure was assessed with two questions, 1) "Did you disclose your HIV status to your partner?" and 2) "Did you disclose your HIV status to others such as other relatives or friends?"

Depression: The Patient Health Questionnaire (PHQ-9) [30] was utilized to screen patients suffering from depression. This 9-item questionnaire asks the patient how emotional problems impact on daily life. The 4-option response format allows scores of $0,1,2$ and 3 to the response categories of "not at all", "several days" "more than half the days" and "nearly every day" respectively. The total PHQ-9 score for the nine items ranges from 0 to 27 and scores of 5, 10, 15, and 20 represent cut points for mild, moderate, moderately severe, and severe depression respectively. Cronbach's alpha for PHQ- 9 was 0.76 in this sample. In this study the cut-point of $\geq 10$ scores was used to identify moderate to severe depression. 
Past month alcohol use was assessed using the Alcohol Use Disorder Identification Test (AUDIT)-C [31]. Cronbach's alpha of AUDIT-C in this sample was 0.74 .

Tobacco use was assessed with four questions, adapted from WHO's Global Adult Tobacco Survey (GATS) [32] by which 1) "Do you currently smoke any tobacco products, such as cigarettes, cigars or pipes?" (If, yes: 2) "Do you currently smoke tobacco products daily?" 3) "Do you currently use any smokeless tobacco, such as snuff, chewing tobacco, betel?" (If, yes: 4) "Do you currently use smokeless tobacco products daily?". Response options were "yes" or "no".

Sexual functioning: An abbreviated 5-items version of the 15-items International Index of Erectile Function (IIEF) to diagnose the presence and severity of erectile dysfunction (ED) [33] was used. The five items selected were based on ability to identify the presence or absence of ED and these are focused on erectile function, e.g., "How do you rate your confidence that you could get and keep an erection?" Responses were scored on a five-point ordinal scale where lower values represent poorer sexual function, with a response of 1 the least functional to a response of 5 the most functional. The possible scores for the IIEF-5 ranged from 5 to 25 (one question has scores of 1-5) and ED is classified into four categories: severe (5-7), moderate (8-11), mild to moderate (12-16), mild (17-21), and no ED (22-25) [33].

Chronic conditions. Patients were asked if they had been diagnosed by a doctor or other health worker with the following conditions: high cholesterol/high blood lipids, heart disease, stroke, cancer, kidney disease, asthma, arthritis, diabetes (high blood sugar), depression, obesity and other. Patients were classified as having comormidity if they had one or more chronic conditions.

Sociodemographic factors assessed included gender, age, marital status, education and occupation.

Medical file information included duration of ART, CD4 count, HIV medication and ART regimen.

\section{Data collection}

Face to face interviews were carried out by one researcher with the target population during times participants were waiting to see doctors, nurses or counsellors. The questionnaire was prepared in English and translated into Myanmar language and back translation was also done. Pre-testing of the questionnaire was completed by 30 HIV-infected adults on ART not involved in the study. The questionnaire set has four main parts: section one, background information; section two, adherence indicators; section three, variables under the IMB model; and section four, moderating factors to ART non-adherence. Data collection was done in a private room of the clinic providing confidentiality of the respondent. It took 30$45 \mathrm{~min}$ for each participant to complete the interview.

\section{Data analysis}

All data was coded, entered and analyzed by using Statistical Package for the Social Sciences (SPSS) for Windows software application program version 21.0. Data was cleaned before subjected to analysis. All data concerning the variables was analyzed using descriptive statistics. Bivariate analysis were done to find associations between independent variables and the outcome. Only the independent variables that were found to be associated to the outcome at bivariate regression analyses were used in the multiple regression model to examine associations between the outcome of ART non-adherence and independent variables. The statistical significant was set at $p$ value $<0.05$.

\section{Results}

\section{Socio-demographics}

Three hundred patients were recruited for this study. The response rate was $98.7 \%$. Among them, $62.3 \%$ were female, $54.3 \%$ were married and the mean age was 41.3 years $(S D=8.7)$ (range 18-66). Almost half of the patients $(42.7 \%)$ had attained primary education level, while $46 \%$ had attained secondary school or higher level education. Over half of the respondents (55.3\%) were working as casual workers, $20.7 \%$ worked in government services or owned a business and $25 \%$ were housewives or unemployed (see Table 1).

\section{Health status and behaviour variables}

Nearly half of the patients (49\%) had been taking ART for one to three years, $42.7 \%$ for over three years and 8.3\% ART for less than one year. The mean CD4 count was $517.5(\mathrm{SD}=263.3)$ cells $/ \mathrm{mm}^{3}$, with a range of 14 to 1425 , and $52.7 \%$ of respondents had CD4 cell counts less than 500 cells $/ \mathrm{mm}^{3}$. Majority of the patients took first line ART drugs (92.3\%) and 57\% took a one time per day regimen with TDF/ABC + 3TC + EFV. Most of the patients $(82.7 \%)$ did not have other co-morbid chronic conditions and $17.3 \%$ had comorbidity such as heart disease, diabetes, hypertension, asthma, kidney disease, rheumatic disease and high cholesterol. Almost one-fifth (16.7\%) engaged in problem drinking, $9.0 \%$ smoked daily, $12.3 \%$ used smokeless tobacco daily and $7.7 \%$ screened positive for moderate to severe depression. The majority $(80.3 \%)$ had disclosed their HIV status to others (outside the partner, such as other relatives and friends). Among male participants, $13.1 \%$ reported mild to moderate ED (see Table 2).

\section{Descriptive statistics on the information-motivation- Behavioural skills ART adherence model}

The mean score of the IMB ART adherence information was $4.0(\mathrm{SD}=2.2)$, with a range of 0-9 scores, the mean score of the IMB ART adherence motivation was $8.7(\mathrm{SD}=1.5)$, with a range of 0-10 scores, 
Table 1 Socio-demographic characteristic of respondents $(N=300)$

\begin{tabular}{|c|c|c|}
\hline Variables & Number & Percent \\
\hline \multicolumn{3}{|l|}{ Gender } \\
\hline Male & 113 & 37.7 \\
\hline Female & 187 & 62.3 \\
\hline Age in years & \multicolumn{2}{|c|}{ Mean \pm SD: $41.3 \pm 8.7$} \\
\hline$<35$ & 79 & 26.3 \\
\hline $35-45$ & 136 & 45.3 \\
\hline$\geq 46$ & 85 & 28.3 \\
\hline \multicolumn{3}{|l|}{ Marital status } \\
\hline Single & 18 & 6.0 \\
\hline Married/cohabiting & 163 & 54.3 \\
\hline Separated/divorced/widowed & 119 & 39.7 \\
\hline \multicolumn{3}{|l|}{ Education } \\
\hline No formal education & 34 & 11.3 \\
\hline Primary school & 128 & 42.7 \\
\hline Secondary school & 84 & 28.0 \\
\hline High school & 40 & 13.3 \\
\hline Graduate level & 14 & 4.7 \\
\hline \multicolumn{3}{|l|}{ Occupation } \\
\hline Own business/ Officer & 62 & 20.7 \\
\hline Housewife/Unemployed & 75 & 25.0 \\
\hline Causal workers & 163 & 54.3 \\
\hline
\end{tabular}

and the mean score of the IMB ART adherence behavioural skills was $11.7(\mathrm{SD}=1.4)$, with a range of 0-14 scores (see Table 3).

\section{Descriptives of ART adherence}

The assessment of ART adherence is summarized in Table 4. The categories of adherence to ART of the respondents were measured by asking them if they missed taking any medication during the past four days and/or past 30 days periods. The mean percentage of adherence of 30-days VAS score was $97.3(\mathrm{SD}=5.0)$, with a range of 80.0-100.0. In order to examine the adherence during the past 30 days, two groups were created using the score of $95 \%$ to benchmark optimal adherence. Among the respondents, $84 \%(n=252)$ reported an adherence scores $\geq 95 \%$ and were allocated to the adherence group and participants with adherence scores $<95 \%$ were allocated to a non-adherence group, representing $16 \%$ of the respondents $(n=48)$. For the four day period prior to the questionnaire administration, patients missing at least one dose of their medication during that period were allocated to the dose non-adherence group and patients missing no dose were allocated to the dose
Table 2 Health status and behaviour variables $(N=300)$

\begin{tabular}{|c|c|c|}
\hline Variables & Number & Percent \\
\hline Duration on ART & \multicolumn{2}{|c|}{ Mean \pm SD: $4.3 \pm 2.1$} \\
\hline$<1$ year & 25 & 8.3 \\
\hline 1-3 year & 147 & 49.0 \\
\hline$>3$ year & 128 & 42.7 \\
\hline Recent CD4 (cells/mm³) & \multicolumn{2}{|c|}{ Mean \pm SD: $517.5 \pm 263.3$} \\
\hline$<500$ & 158 & 52.7 \\
\hline $500-1000$ & 122 & 40.7 \\
\hline$>1000$ & 20 & 6.7 \\
\hline \multicolumn{3}{|l|}{ HIV medication } \\
\hline ART first line drugs & 277 & 92.3 \\
\hline ART second line drugs & 23 & 7.7 \\
\hline \multicolumn{3}{|l|}{ ART Regimen } \\
\hline $\mathrm{TDF} / \mathrm{ABC}+3 \mathrm{TC}+\mathrm{EFV}$ (one time/day) & 171 & 57.0 \\
\hline$A Z T / A B C+3 T C+N V P / L P V / r(2$ times/day) & 129 & 43.0 \\
\hline \multicolumn{3}{|l|}{ Co-morbid diseases } \\
\hline Absence of co-morbidity & 248 & 82.7 \\
\hline Presence of co-morbidity & 52 & 17.3 \\
\hline Past month alcohol use & 50 & 16.7 \\
\hline Smokes tobacco daily & 27 & 9.0 \\
\hline Smokeless tobacco use daily & 37 & 12.3 \\
\hline Disclosure of HIV status to others & 241 & 80.3 \\
\hline Moderate to severe depressive symptoms & 23 & 7.7 \\
\hline Internalized stigma (Range:0-7) & Mean \pm SD & $2.7 \pm 2.3$ \\
\hline No stigmatization & 67 & 22.3 \\
\hline Low stigmatization & 132 & 44.0 \\
\hline High stigmatization & 101 & 33.7 \\
\hline Social support (Range 3-12) & Mean \pm SD & $9.7 \pm 2.0$ \\
\hline Less & 194 & 64.7 \\
\hline High & 106 & 35.3 \\
\hline $\begin{array}{l}\text { Sex functioning among male respondent } \\
(n=107) \text { (Range 5-25) }\end{array}$ & \multicolumn{2}{|c|}{ Mean \pm SD: $18.9 \pm 2.7$} \\
\hline No erectile dysfunction (ED) & 49 & 45.8 \\
\hline Mild ED & 44 & 41.1 \\
\hline Mild to moderate ED & 14 & 13.1 \\
\hline
\end{tabular}

TDF Tenofovir, ABC Abacavir, 3TC Lamivudine, EFV Efavirenz, AZT Zidovudine, NVP Nevirapine, $L P V / r$ Lopinavir/ritonavir, $S D$ standard deviation

adherence group. It was seen that twenty nine patients (9.7\%) reported having missed at least one dose appointment during the past four days while most of them reported having no skipped dose (90.3\%). All the respondents who had missed their dose were asked the reasons for this behaviour. As shown in Table 4, the major reason given for non-compliance were being too busy with other things (23\%), away from home (17.7\%), or forgetfulness (12.3\%). 
Table 3 Information-motivation-behavioural skills model

\begin{tabular}{|c|c|c|}
\hline Variables & $\mathrm{N}$ or Mean & $\%$ or $\mathrm{SD}$ \\
\hline IMB adherence information ${ }^{\mathrm{a}}$ & Mean \pm SD & $4.0 \pm 2.2$ \\
\hline Low & 122 & 40.7 \\
\hline Moderate & 90 & 30.0 \\
\hline High & 88 & 29.3 \\
\hline IMB adherence motivation $^{a}$ & Mean \pm SD & $8.7 \pm 1.5$ \\
\hline Low & 54 & 18.0 \\
\hline Moderate & 118 & 39.3 \\
\hline High & 128 & 42.7 \\
\hline IMB behavioral skills ${ }^{a}$ & Mean \pm SD & $11.7 \pm 1.4$ \\
\hline Low & 111 & 37.0 \\
\hline Moderate & 91 & 30.3 \\
\hline High & 98 & 32.7 \\
\hline
\end{tabular}

SD standard deviation

${ }^{\text {a }}$ higher score $=$ higher adherence information, motivation and behavioural skills

Associations with ART non-adherence in the past 30 days The result of bivariate analysis revealed a statistically significant association with ART non-adherence in patients working as own business and government officers compared to those who are working as housewife and unemployed or causal workers $(p=0.039)$. Patients who had moderate scores on ART information were more

Table 4 ART non-adherence

\begin{tabular}{lll}
\hline Variable & Number & Percent \\
\hline 30 days VAS & & \\
$\geq 95 \%$ adherence & 252 & 84.0 \\
$\quad$ (95\% adherence & 48 & 16.0 \\
Self-report 4 days recall dose adherence & & \\
Adherence & 271 & 90.3 \\
Non-adherence & 29 & 9.7 \\
Reasons for missed medication $(n=130)$ & & \\
Busy & 69 & 23.0 \\
Away home & 53 & 17.7 \\
Forget & 37 & 12.3 \\
Change in daily routine & 23 & 7.7 \\
Asleep & 15 & 5.0 \\
Sick & 13 & 4.3 \\
Not want others to notice & 8 & 2.7 \\
Side effects & 6 & 2.0 \\
Too many pills & 4 & 1.3 \\
Problems with taking pill & 4 & 1.3 \\
Depressed & 3 & 1.0 \\
Feel toxic & 2 & 0.7 \\
Ran out of pills & 2 & 0.7 \\
\hline
\end{tabular}

VAS Visual Analog Scale likely to be non-adherence to ART ( $p=0.005)$ than patients with low scores on ART information. PLHIV who had higher scores on behavioural skills to take the medication reported better adherence than those who had low and moderate scores in behavioural skills ( $p=0.048)$. Problem drinking, smoking daily and daily smokeless tobacco use were found to be associated with ART nonadherence ( $p=0.038,0.007$ and 0.005 , respectively). The patients who had disclosed their HIV status to others were more likely to be non-adherent to ART than those who had not disclosed $(p=0.018)$. The patients whose partner was not on ART were more likely non-adherent than patients who had a partner on ART $(p=0.002)$. Men who had mild to moderate ED had a higher odds to nonadherence than those without or mild ED ( $p=0.008)$.

In multivariable logistic regression analysis, poor IMB ART adherence behavioural skills, daily smokeless tobacco use, having disclosed their HIV status to others, having a partner who was not on ART, and among men mild to moderate ED was associated with ART nonadherence. Due to few cases with ED, confidence intervals are wide (see Table 5).

\section{Discussion}

The prevalence of adherence to ART was $84 \%$ measured by the 30 days VAS adherence measure in this study. Among the 300 PLHIV in the study, 16\% reported a failure to adhere to ART during the past month. The proportion of adherence was found to be different than the results of the most recent ART adherence study in Myanmar which reported 76.2\% adherence in 2016 [34]. The discrepancy might be due to adherence measurement tools (pill identification test versus VAS within 30 days). There were also differences in the socioeconomic status of the two studies in terms of the target population and the studies were conducted in different treatment settings as well. The aforementioned study was undertaken at a public sector site whilst this current study was conducted in the private sector. A possible reason for the different prevalence of ART adherence between the two settings include a better patient provider ratio and the affiliated consultation time for clients in a private sector setting with relatively better resources than in the public sector [19]. In fact, in this study, the level of adherence was comparable with other studies across the Southeast Asian region where ART adherence varied widely from $60 \%$ to $77 \%[12,35,36]$.

In this study, socio-demographic characteristics of the respondents were not associated with ART nonadherence. Furthermore, previous research has also shown no associaation with gender and non-adherence outcomes, similar to our study [37]. In spite of employment being a contributing factor as financial barrier to patients according to the literature [38], the current 
Table 5 Prevalence of and associations with ART non-adherence in the past 30 days

\begin{tabular}{|c|c|c|c|c|c|c|}
\hline Variable & $\mathrm{n}$ & $\%$ & COR (95\% Cls) & $P$-value & AOR (95\% Cls) & $P$-value \\
\hline \multicolumn{7}{|l|}{ Gender } \\
\hline Female & 25 & 13.4 & 1 (Reference) & & & \\
\hline Male & 23 & 20.4 & $1.66(0.89-3.09)$ & 0.112 & & \\
\hline \multicolumn{7}{|l|}{ Age (years) } \\
\hline$<35$ & 16 & 20.3 & 1 (Reference) & & & \\
\hline $36-45$ & 20 & 14.7 & $0.68(0.33-1.40)$ & 0.295 & & \\
\hline 46 and above & 12 & 14.1 & $0.65(0.29-1.47)$ & 0.299 & & \\
\hline \multicolumn{7}{|l|}{ Marital status } \\
\hline Single & 5 & 27.8 & 1 (Reference) & & & \\
\hline Married/cohabiting & 28 & 17.2 & $0.54(0.18-1.63)$ & 0.275 & - & \\
\hline Separated/divorced/ widowed & 15 & 12.6 & $0.38(0.12-1.20)$ & 0.099 & & \\
\hline \multicolumn{7}{|l|}{ Education } \\
\hline Primary and less & 24 & 14.8 & 1 (Reference) & & & \\
\hline Secondary and above & 24 & 17.4 & $1.21(0.65-2.25)$ & 0.544 & - & \\
\hline \multicolumn{7}{|l|}{ Occupation } \\
\hline Housewife/student/unemployed & 8 & 10.7 & 1 (Reference) & & & \\
\hline Own business/officers & 15 & 24.2 & $2.67(1.05-6.81)$ & 0.039 & $1.43(0.54-3.82)$ & 0.474 \\
\hline Casual worker & 25 & 15.3 & $1.52(0.65-3.54)$ & 0.335 & $1.34(0.44-4.98)$ & 0.789 \\
\hline \multicolumn{7}{|l|}{ Duration on ART } \\
\hline$>3$ years & 26 & 20.3 & 1 (Reference) & & & \\
\hline $1-3$ years & 18 & 12.2 & $0.55(0.28-1.05)$ & 0.071 & - & \\
\hline$<1$ year & 4 & 16.0 & $0.75(0.24-2.37)$ & 0.620 & & \\
\hline \multicolumn{7}{|l|}{ Recent CD4 count } \\
\hline$\geq 500-1000$ & 23 & 16.2 & 1 (Reference) & & & \\
\hline$<500$ & 25 & 15.8 & $0.97(0.52-1.80)$ & 0.930 & - & \\
\hline \multicolumn{7}{|l|}{ HIV medication } \\
\hline ART first line drugs & 45 & 16.2 & 1 (Reference) & & & \\
\hline ART second line drugs & 3 & 13.0 & $0.77(0.22-2.71)$ & 0.688 & - & \\
\hline \multicolumn{7}{|l|}{ ART regimen } \\
\hline $\mathrm{TDF} / \mathrm{ABC}+3 \mathrm{TC}+\mathrm{EFV}$ & 23 & 13.5 & 1 (Reference) & & & \\
\hline $\mathrm{AZTT} / \mathrm{ABC}+3 \mathrm{TC}+\mathrm{NVP} / \mathrm{LPV} / \mathrm{r}$ & 25 & 19.4 & $1.55(0.83-2.87)$ & 0.167 & - & \\
\hline \multicolumn{7}{|l|}{ Diagnosis of chronic disease } \\
\hline No chronic disease & 42 & 16.9 & 1 (Reference) & & & \\
\hline Has chronic disease & 6 & 11.5 & $1.56(0.63-3.90)$ & 0.338 & - & \\
\hline \multicolumn{7}{|l|}{ IMB adherence information } \\
\hline Low & 13 & 10.7 & 1 (Reference) & & 1 (Reference) & \\
\hline Moderate & 23 & 25.6 & $2.87(1.37-6.06)$ & 0.005 & $1.96(0.67-5.74)$ & 0.222 \\
\hline High & 12 & 13.6 & $1.32(0.57-3.06)$ & 0.511 & $0.58(0.17-1.96)$ & 0.380 \\
\hline \multicolumn{7}{|l|}{ IMB adherence motivation } \\
\hline Low & 7 & 13.0 & 1 (Reference) & & & \\
\hline Moderate & 18 & 15.3 & $1.21(0.47-3.09)$ & 0.693 & - & \\
\hline High & 23 & 18.0 & $1.47(0.59-3.67)$ & 0.408 & & \\
\hline \multicolumn{7}{|l|}{ IMB adherence behavioural skills } \\
\hline Low & 24 & 21.6 & 1 (Reference) & & 1 (Reference) & \\
\hline
\end{tabular}


Table 5 Prevalence of and associations with ART non-adherence in the past 30 days (Continued)

\begin{tabular}{|c|c|c|c|c|c|c|}
\hline Moderate & 13 & 14.3 & $0.60(0.29-1.27)$ & 0.183 & $0.37(0.13-1.07)$ & 0.066 \\
\hline High & 11 & 11.2 & $0.45(0.21-0.99)$ & 0.048 & $0.31(0.10-0.94)$ & 0.039 \\
\hline Past month alcohol use (base = no) & 13 & 26.0 & $2.16(1.04-4.46)$ & 0.038 & $0.80(0.25-2.55)$ & 0.702 \\
\hline Smokes tobacco daily (base = no) & 16 & 28.1 & $2.57(1.29-5.12)$ & 0.007 & $2.38(0.85-6.65)$ & 0.098 \\
\hline Smokeless tobacco use daily (base $=$ no) & 23 & 25.3 & $2.49(1.32-4.68)$ & 0.005 & $3.22(1.28-8.12)$ & 0.013 \\
\hline Non-disclosure of HIV status to others (base = yes) & 3 & 5.1 & $0.23(0.07-0.78)$ & 0.018 & $0.07(0.01-0.69)$ & 0.022 \\
\hline Low social support (base = high) & 32 & 16.5 & $1.11(0.58-2.14)$ & 0.752 & - & \\
\hline \multicolumn{7}{|l|}{ Internalized stigma } \\
\hline No stigmatization & 8 & 11.9 & 1 (Reference) & & & \\
\hline Low stigmatization & 26 & 19.7 & $1.80(0.77-4.25)$ & 0.174 & - & \\
\hline High stigmatization & 14 & 13.9 & $1.19(0.47-3.01)$ & 0.718 & & \\
\hline Partner who is not on ART & 19 & 23.2 & $3.34(1.58-7.07)$ & 0.002 & $4.25(1.70-10.64)$ & 0.002 \\
\hline Moderate to severe depression symptoms (base $=$ no) & 4 & 17.4 & $1.12(0.36-3.44)$ & 0.850 & - & \\
\hline Erectile dysfunction among male respondents (base $=$ no) & 15 & 25.9 & $6.00(1.61-22.42)$ & 0.008 & $15.14(1.41-162.66)$ & 0.025 \\
\hline
\end{tabular}

IMB Information, Motivation and Behavioural skills, COR Crude Odds Ratio, AOR Adjusted Odd Ratio, Cls = Confident Intervals

study did not reflect this finding since the clinic provided all care free of charge. For adherence related to IMB model, the present study shows that behavioural skills was associated with self-report VAS adherence in both bivariate and multivariate analysis which is consistent with findings from other studies [39, 40]. Findings are logical in the sense that if patients have more selfefficacy themselves, they are better equipped to reach the goal of optimal adherence.

For behaviour variables of moderating factors, tobacco users were significantly associated with non-adherence in our study which is consistent with previous Myanmar study findings where non-smokers were more likely to adhere to ART [34]. We found an increased risk of nonadherence among individuals who had disclosed their HIV status to others and this finding was inconsistent with other studies [41]. Surprisingly, having disclosed to others was associated with non-adherence to treatment. This might have happened because in this study, being a cross-sectional one, could not provide materialistic relations between the two variables. Having a partner on ART was a strong predictor of adherence to ART. This finding supports the role of HIV service providers and counsellors to emphasize couple counselling and encourage HIV testing to discordant couples. In this study, male respondents were assessed regarding sexual functioning during the past six months since previous literature reported increasing occurrence of sexual dysfunction among patients on ART [37]. Among 107 respondents men (as 6 men denied to answer to IIEF questionnaire), 54.2\% reported some degree of dysfunction in sexual activities, therefore more than half of patients reporting some degree of erectile dysfunction, similar to other studies [42]. The finding in the present study of an association between sexual dysfunction and non-adherence to ART was confirmed, as found in several previous studies [14, 43].

\section{Study limitations}

This cross-sectional study has several limitations. The ART adherence levels may be overestimated and highly subjective due to self-reporting, and may be prone to recall bias. In order to minimize this bias, however, the answers were reconfirmed and the clients were provided with enough time to remember event. Also, although all participants were invited to participate, the study may have a selection bias, because participants were patients on ART treatment who came to the clinic at the time of data collection. This excluded patients who were not retained in the clinic and also patients who missed clinical appointments during the period. Moreover, the crosssectional nature of the study design limited the ability of the analysis to determine the direction of the causation. The data were collected from only one private sector clinic of one region in Myanmar, so it is not generalizable to other regions and also the public sector sites.

\section{Conclusions}

The proportion of adherence in this current study was relatively high compared with other studies conducted in Southeast Asia. Around eight out of ten patients who were taking ART reported good adherence to ART. However, suboptimal adherence within some certain subgroups is still a challenging issue. Innovative approaches including daily mobile phone reminders and provision and use of memory aids could be trialled for improving adherence for patients with identified risk factors. Certainly, the present study suggests that the IMB model represented adherence within this sample, as 
behavioural skills were critical and intervention approaches should be tailored to the targeted population. An important recommendation of this study is that care and support for the people who reported substance use should be included a comprehensive core package of HIV management including risk assessment and behaviour change communication tailored to individual patient's lifestyles.

\section{Abbreviations}

AACTG: Adult AIDS Clinical Trials Group; AIDS: Acquired immunodeficiency syndrome; ART: Anti-Retroviral Therapy; ARV: Anti-retroviral drugs; AUDIT: Alcohol Use Disorder Identification Test; ED: Erectile Dysfunction; GFATM: Global Fund for AIDS, TB and Malaria; HAART: Highly Active Anti-Retroviral Therapy; HIV: Human immunodeficiency virus; IIEF: International Index of Erectile Function; IMB model: Information, Motivation and Behavioural Skills Model; LW-IMBAAQ: Information-Motivation-Behavioral Skill ART Adherence questionnaire; PLHIV: People living with HIV; VAS: Visual Analog Scale

\section{Acknowledgements}

We would like to acknowledge International Organization for Migration (IOM), Myanmar. Support of the IOM HIV clinic team in carrying out interviews is also acknowledged. This study was carried out at the HIV clinic in Mawlamyine administered by the International organization for Migration, Myanmar under the funding of the Global Fund for AIDS, TB and Malaria (GFATM). We would also like to thank the patients for their contribution towards the success of this study.

\section{Funding}

Not applicable.

\section{Availablilty of data and materials}

The dataset generated during the current study are not publically available for ethical requirements. Participant consent form was not given for data to be provided to third party.

\section{Authors' contributions}

Conceived and designed the experiments by WLA, AP, KP. Carried out all field assessment related to the study by WLA. Statistical analysis by WLA, KP. Contributed to the writing of the manuscript: WLA, KP, AP. All authors have read and approved the final version of this manuscript.

\section{Competing interests}

The authors declare that they have no competing interests.

\section{Consent for publication}

Not applicable.

\section{Ethics approval and consent to participate}

The study protocol was approved by the Ethical Review Board of Mahidol University (certificate of approval number: 2016/120.2903) and the Ethical Review Committee of the Department of Medical Research, Myanmar (approval number-Ethics/DMR/2016/042). Written informed consent was sought from each participant prior to the interview.

\section{Publisher's Note}

Springer Nature remains neutral with regard to jurisdictional claims in published maps and institutional affiliations.

\footnotetext{
Author details

${ }^{1}$ Master of Primary Health Care Management Program, ASEAN Institute for Health Development, Mahidol University, Nakhonpathom, Thailand. ${ }^{2}$ International Organization for Migration, Kamayut Township, Yangon, Myanmar. ${ }^{3}$ ASEAN Institute for Health Development, Mahidol University, Nakhonpathom, Thailand. ${ }^{4}$ Department of Research and Innovation, University of Limpopo, Sovenga, South Africa. ${ }^{5} \mathrm{HIV} / \mathrm{STI}$ and TB Research Programme, Human Sciences Research Council, Pretoria, South Africa.
}

Received: 20 August 2016 Accepted: 26 April 2017

Published online: 05 May 2017

\section{References}

1. UNAIDS. Fast-track:ending the AIDS epdermis by 2030; 2014. Available at: http:// www.unaids.org/sites/default/files/media_asset/JC2686_WAD2014report_en.pdf

2. Sohn A, Cho B, Kennedy HA. Identifying barriers to Human immunodeficiency virus testing for men who have sex with men in South Korea. Osong Public Health. 2015;6(3):192-200.

3. UNAIDS. The gap report. 2014. Available at: http://www.unaids.org/en/resources/ documents/2014/20140716_UNAIDS_gap_report.

4. Brechtl JR, Breitbart W, Galietta M, Krivo S, Rosenfeld B. The use of highly active antiretroviral therapy (HAART) in patients with advanced HIV infection: impact on medical, palliative care, and quality of life outcomes. J Pain Symptom Manage. 2001;21(1):41-51.

5. UNAIDS. 90-90-90: an ambitious treatment target to help end the AIDS epidemic. 2014. Available at: http://www.unaids.org/en/resources/documents/2014/90-90-90.

6. WHO. Consolidated guidelines on the use of antiretroviral drugs for treating and prevention HIV infection. Geneva: WHO; 2015. Available at: http://apps. who.int/iris/bitstream/10665/198064/1/9789241509893_eng.pdf?ua=1

7. Chalker J, Andualem T, Tadeg H, Gitau L, Ntaganira J, Obua C, et al.(2009). Developing standard methods to monitor adherence to antiretroviral medicines and treatment defaulting in resource-poor settings. Essential Medicine Monitor. Available at: http://www.who.int/medicines/publications/ monitor/EMM_art3lssue_1_2009.pdf?ua=1 (Accessed 20 June 2016).

8. Paterson DL, Swindells S, Mohr J, Brester M, Vergis EN, Squier C, et al. Adherence to protease inhibitor therapy and outcomes in patients with HIV infection. Ann Intern Med. 2000;133(1):21-30.

9. Bam K, Rajbhandari RM, Karmacharya DB, Dixit SM. Strengthening adherence to anti retroviral therapy (ART) monitoring and support: operation research to identify barriers and facilitators in Nepal. BMC Health Serv Res. 2015;15:188.

10. WHO. Guideline on when to start antiretroviral therapy and on preexposure prophylaxis for HIV. Geneva: World Health Organization; 2015. Available at: http://www.who.int/hiv/pub/guidelines/earlyrelease-arv/en/

11. Teshome W, Belayneh M, Moges M, Endrias M, Mekonnen E, Ayele S, et al. Who takes the medicine? Adherence to antiretroviral therapy in southern Ethiopia. Patient Prefer Adherence. 2015;9:1531-7.

12. Hansana V, Sanchaisuriya P, Durham J, Sychareun V, Chaleunvong K Boonyaleepun S, et al. Adherence to antiretroviral therapy (ART) among people living with HIV (PLHIV): a cross-sectional survey to measure in Lao PDR. BMC Public Health. 2013;13:617.

13. Pahari S, Roy S, Mandal A, Kuila S, Panda S. Adherence to anti-retroviral therapy \& factors associated with it: a community based cross-sectional study from West Bengal, India. Indian J Med Res. 2015;142(3):301.

14. Adebimpe WO, Omobuwa O, Adeoye OA. Prevalence and predictors of erectile dysfunctions among men on antiretroviral therapy in South-western Nigeria. Ann Med Health Sci Res. 2015;5(4):279-83.

15. Collazos J, Martinez E, Mayo J, Ibarra S. Sexual dysfunction in HIV-infected patients treated with highly active antiretroviral therapy. J Acquir Immune Defic Syndr. 2002;31(3):322-6.

16. Mugavero MJ, Lin HY, Willig JH, Westfall AO, Ulett KB, Routman JS, et al. Missed visits and mortality among patients establishing initial outpatient HIV treatment Clin Infect Dis. 2009:48(2):248-56.

17. Mugavero MJ, Westfall AO, Zinski A, Davila J, Drainoni ML, Gardner LI, et al. Measuring retention in HIV care: the elusive gold standard. J Acquir Immune Defic Syndr. 2012;61(5):574-80.

18. Sabapathy K, Ford N, Chan KN, Kyaw MK, Elema R, Smithuis F, et al. Treatment outcomes from the largest antiretroviral treatment program in Myanmar (Burma): a cohort analysis of retention after scale-up. J Acquir Immune Defic Syndr. 2012:60(2):e53-62.

19. Thida A, Tun ST, Zaw SK, Lover AA, Cavailler P, Chunn J, et al. Retention and risk factors for attrition in a large public health ART program in Myanmar: a retrospective cohort analysis. PLoS One. 2014;9(9):e108615.

20. Crawford TN, Sanderson WT, Thornton A. Impact of poor retention in HIV medical care on time to viral load suppression. J Int Assoc Provid AIDS Care. 2014:13(3):242-9.

21. Chaiyachati KH, Ogbuoji O, Price M, Suthar AB, Negussie EK, Bärnighausen T. Interventions to improve adherence to antiretroviral therapy: a rapid systematic review. AIDS. 2014;28(Suppl 2):S187-204. 
22. Wekesa E. ART adherence in resource poor settings in sub-Saharan Africa: a multidisciplinary review. 2007. Avaiable at: http://uaps2007.princeton.edu/ papers/70123.

23. Chesney MA. Factors affecting adherence to antiretroviral therapy. Clin Infect Dis. 2000;30(Suppl 2):S171-6.

24. Emamzadeh-Fard S, Fard SE, SeyedAlinaghi S, Paydary K. Adherence to antiretroviral therapy and its determinants in HIV/AIDS patients: a review. Infect Disord Drug Targets. 2012;12(5):346-56.

25. Chesney MA, Ickovics JR, Chambers DB, Gifford AL, Neidig J, Zwickl B, et al. Self-reported adherence to antiretroviral medications among participants in HIV clinical trials: the AACTG adherence instruments. Patient Care Committee \& Adherence Working Group of the outcomes Committee of the Adult AIDS Clinical Trials Group (AACTG). AIDS Care. 2000;12(3):255-66.

26. Maneesriwongul WL, Tulathong S, Fennie KP, Williams AB. Adherence to antiretroviral medication among HIV-positive patients in Thailand. J Acquir Immune Defic Syndr. 2006;43:S119-22.

27. The Life Windows Project Team. The Life Windows Information Motivation Behavioral Skills ART Adherence Questionnaire (LW-IMB-AAQ). 2006. Center for Health, Intervention, and Prevention. University of Connecticut. Available at: http://chipcontent.chip.uconn.edu/chipweb/documents/Research/F_ LWIMBARTQuestionnaire.pdf. Accessed 20 Apr 2016.

28. Brock DM, Sarason IG, Sarason BR, Pierce GR. Simultaneous assessment of perceived global and relationship-specific support. J Soc Pers Relat. 1996;13(1):143-52

29. Kalichman SC, Simbayi LC, Jooste S, Toefy Y, Cain D, Cherry C, et al. Development of a brief scale to measure AIDS-related stigma in South Africa. AIDS Behav. 2005;9(2):135-43.

30. Kroenke K, Spitzer RL, Williams JB. The PHQ-9: validity of a brief depression severity measure. J Gen Intern Med. 2001;16(9):606-13.

31. Bush Bush K, Kivlahan DR, McDonell MB, Fihn SD, Bradley KA. The AUDIT alcohol consumption questions (AUDIT-C): an effective brief screening test for problem drinking. Ambulatory care quality improvement project (ACQUIP). Alcohol use disorders identification test. Arch Intern Med. 1998;158(16):1789-95.

32. Global Adult Tobacco Survey Collaborative Group. Tobacco questions for surveys: a subset of key questions from the global adult tobacco survey (GATS). Second ed. Atlanta: Centers for Disease Control and Prevention; 2011

33. Rosen RC, Cappelleri JC, Smith MD, Lipsky J, Pena BM. Development and evaluation of an abridged, 5-item version of the International index of erectile function (IIEF-5) as a diagnostic tool for erectile dysfunction. Int J Impot Res. 1999;11(6):319-26.

34. Thandar M, Mon A, Boonyaleepun S, Laohasiriwong W. Antiretroviral treatment adherence and associated factors among people living with HIV in developing country, Myanmar. Int J Community Med Public Health. 2016;3(5):1318-25.

35. Weaver ER, Pane M, Wandra T, Windiyaningsih C, Herlina, Samaan G. Factors that influence adherence to antiretroviral treatment in an urban population, Jakarta, Indonesia. PLoS One. 2014;9(9):e107543.

36. Tran BX, Nguyen LT, Nguyen NH, Hoang QV, Hwang J. Determinants of antiretroviral treatment adherence among HIV/AIDS patients: a multisite study. Glob Health Action. 2013;6:19570

37. Do HM, Dunne MP, Kato M, Pham CV, Nguyen KV. Factors associated with suboptimal adherence to antiretroviral therapy in Viet Nam: a cross-sectional study using audio computer-assisted self-interview (ACASI). BMC Infect Dis. 2013;13:154

38. Joglekar N, Paranjape R, Jain R, Rahane G, Potdar R, Reddy KS, et al. Barriers to ART adherence \& follow ups among patients attending ART centres in Maharashtra, India. Indian J Med Res. 2011;134(6):954-9.

39. Santillan Torres Torija C, Villagran Vazquez G, Robles Montijo SS, de Lourdes Eguiluz Romo $L$. The information and motivation and behavioral skills model of ART adherence among HIV-positive adults in Mexico. J Int Assoc Provid. 2015;14(4):335-42.

40. Hawkins A, Evangeli M, Sturgeon K, Le Prevost M, Judd A. Episodic medication adherence in adolescents and young adults with perinatally acquired HIV: a within-participants approach. AIDS Care. 2016;28(Suppl 1):68-75.

41. Tsega B, Srikanth BA, Shewamene Z. Determinants of non-adherence to antiretroviral therapy in adult hospitalized patients, Northwest Ethiopia. Patient Prefer Adherence. 2015;9:373-80.

42. Lallemand F, Salhi Y, Linard F, Giami A, Rozenbaum W. Sexual dysfunction in 156 ambulatory HIV-infected men receiving highly active antiretroviral therapy combinations with and without protease inhibitors. J Acquir Immune Defic Syndr. 2002;30(2):187-90

43. Trotta MP, Ammassari A, Murri R, Marconi P, Zaccarelli M, Cozzi-Lepri A, et al. Self-reported sexual dysfunction is frequent among HIV-infected persons and is associated with suboptimal adherence to antiretrovirals. AIDS Patient Care STDS. 2008;22(4):291-9.

\section{Submit your next manuscript to BioMed Central and we will help you at every step:}

- We accept pre-submission inquiries

- Our selector tool helps you to find the most relevant journal

- We provide round the clock customer support

- Convenient online submission

- Thorough peer review

- Inclusion in PubMed and all major indexing services

- Maximum visibility for your research

Submit your manuscript at www.biomedcentral.com/submit

) Biomed Central 